\section{The Virtual Anatomy Lab: an eDemonstrator pedagogical agent can simulate student-faculty interaction and promote student engagement}

\author{
Jonathan Weber, Maxwell Hincke, \\ Beata Patasi, Alireza Jalali, \\ Nadine Wiper-Bergeron \\ Division of Clinical and Functional \\ Anatomy, Department of Cellular \\ and Molecular Medicine, University \\ of Ottawa, Ontario, Canada
}

\section{Abstract}

As medical curricula evolve, many universities have adopted a clinical case-centered medical curriculum with a strong focus on small group learning and reduction of traditional lectures such that anatomy has become a selftaught subject supported by e-learning modules. One caveat of this approach is decreased student-faculty interaction and reduced student engagement. Thus use of e-learning must be balanced with the need for continued student-faculty interaction to promote healthy student engagement. To both support selfdirected learning of anatomy and to simulate student-faculty interaction, we created the Virtual Anatomy Lab (VAL) that features a human pedagogical agent, called the eDemonstrator, who guides student navigation through the available learning resources. The VAL was evaluated using a mixed methods approach (usage statistics and focus groups) by two medical student populations at the University of Ottawa: first year medical students in a revised curriculum where anatomy lectures were abolished and laboratory sessions were self-taught, and second year medical students in the former curriculum in which anatomy lectures were given in advance of each laboratory session. We conclude that online modules such as the VAL, well designed with a human pedagogical agent, can be used within the curriculum without negatively impacting student engagement. Ethical Approval for this study was obtained from the Ottawa Hospital Research Ethics Board (protocol number \#2009055-01H).

\section{Introduction}

Medical programs are constantly in flux, seeking to adapt curricula to better prepare graduates for clinical training and licensing.
Following the release of the report of Project Panel on the General Professional Education of the Physician and College Preparation for Medicine many medical schools have modernized their curricula to incorporate recommendations such as reduced lecture hours, increased study time, and more small-group learning. ${ }^{1}$ As a result, many North American universities including the University of Ottawa have moved towards a clinical case-centered curriculum with a strong focus on small group learning and collaboration and a concomitant de-emphasis of traditional lectures and laboratory sessions.

In 2008-2009, the University of Ottawa introduced a redesigned medical curriculum driven by the dual objectives of enhancing horizontal integration of topics and increasing pre-clerkship exposure to clinical medicine. The changes reduced lecture time to a maximum of 4 hours per week, and whereas anatomy was once covered in both a lecture and a lab, in the new curriculum, anatomy lab sessions follow a team-based learning format without lectures, requiring students to arrive prepared to teach the anatomy to their peers. ${ }^{2-5}$

One of the ways that medical faculty can assist student-directed learning is to provide learning resources that are accessible via the Internet. One on the caveats of this approach is decreased student-faculty interaction and the threat of decreased student engagement. Student engagement can be broken down into three components: social engagement (relationship with peers and faculty), academic engagement (participation for success and achievement), and intellectual engagement (cognitive investment towards mastery of the subject matter). ${ }^{6}$ All three components rely on student commitment and a productive relationship with faculty and peers.

\section{Innovation}

We took advantage of the fact that in our revised curriculum, the musculoskeletal anatomy content was moved from the second year of studies to the beginning of the first year. Thus for one year, the outgoing students and the new students were both studying musculoskeletal anatomy at the same time, using the same learning objectives, through two different methods.

Using the Seven Principles of Good Practice as a guide, ${ }^{7,8}$ we created the Virtual Anatomy Laboratory (VAL), featuring a human pedagogical agent that we named the eDemonstrator. A pedagogical agent is a virtual representation of an instructor, and can be animated or not. ${ }^{9,10}$ These agents have been shown to increase student engagement, increase student arousal, motivate student learning and make learning
Correspondence: Nadine Wiper-Bergeron,

Division of Clinical and Functional Anatomy, Department of Cellular and Molecular Medicine, University of Ottawa, 451 Smyth Road, Ottawa, Ontario, K1H 8M5 Canada.

Tel. +1.613.562.5800.

E-mail: nadine.wiperbergeron@uottawa.ca

Key words: anatomy, pedagogical agent, virtual learning environment, undergraduate medical education.

Acknowledgements: the authors wish to acknowledge Megan Rose for her participation as a focus group facilitator. For technical and administrative support, we thank Shannon Goodwin, Henri Lescault, Daniel Trottier, Monica ForeroMcGrath, Serge Bisson and Claudine Séguin. The authors would also like to thank Dr. Jacqueline Carnegie for critical reading of the manuscript and for many insightful discussions. Results of this study were presented at the Canadian Network for Innovation in Education Conference held in Ottawa, Ontario in 2009 and the Academy for Innovation in Medical Education (u0ttawa) Day in 2010.

Funding: funding for this project was provided by grants to N.W.B from the Academy for Innovation in Medical Education (AIME) and from the Centre for University Teaching, Ottawa.

Received for publication: 12 April 2012.

Revision received: 30 May 2012.

Accepted for publication: 11 June 2012.

This work is licensed under a Creative Commons Attribution NonCommercial 3.0 License (CC BYNC 3.0).

(C) Copyright J. Weber et al., 2012

Licensee PAGEPress srl, Italy

Medical Education Development 2012; 2:e5 doi:10.4081/med.2012.e5

experiences more enjoyable in the online environment in other disciplines. ${ }^{9-12}$ Thus, the design of the VAL is unique in that it was conceived to support both self-directed learning while striving to capture some of the one-onone experience with a professor that is lacking in online learning experiences. The intersection of the two cohorts offered us the opportunity to evaluate the VAL as a learning tool, and more importantly, to evaluate whether the use of the pedagogical agent could simulate student-faculty interaction.

The VAL web site was created using Adobe Dreamweaver CS3 as a collection of learning resources tied together by the eDemonstrator pedagogical agent. The coding was completed by J. Weber, as part of a cooperative work placement, keeping the overall costs for the development of the VAL low (under $\$ 12,000 \mathrm{CDN}$ ). The VAL was populated with the following learning resources: virtual lectures, video demonstra- 
tions, study notes, enhanced visual learning and quizzes that were all prepared by content experts. Virtual lectures were developed by synchronizing a PowerPoint slide presentation with an audio voice over featuring the eDemonstrator's voice using SoundSlides. No virtual lecture exceeded 30 minutes in duration. Video demonstrations were captured in laboratory using a Canon GL2 camera without sound capture. Captured video was edited and merged with audio voice over using Adobe Premiere CS3 and published as an Adobe Flash video for web use. Study notes are essentially short text documents summarizing key information, covering all learning objectives, and packaged as a PDF document. Enhanced Visual Learning consists of a series of images of cadaveric specimens of which labeling and highlighting of structures can be toggled by mouse-over, and was developed using Adobe Flash. Quizzes were designed by synchronizing a PowerPoint presentation of sequential questions and answers with the sound of a bell using SoundSlides. These formative quizzes were meant to simulate the bell-ringer practical exams used in the curriculum both in style and in content while providing immediate feedback. Each learning resource was presented in a theme specific for the tool. For example, virtual lectures were presented projected on a lecture theatre screen while video demonstrations are seen as projected in the anatomy laboratory.

Within the VAL, the eDemonstrator explains the learning objectives and guides students to the resources. Her voice is used for the lectures and the video demonstrations, and thus serves to link the VAL together as a cohesive learning environment. The VAL is available for educational purposes at: http://www.med.uottawa.ca/Research/eDemonstrator/eng/.

We populated the VAL with content for three weeks of study, covering the hip, the knee and the ankle. While the content of the VAL covered exactly the learning objectives for both cohorts of students, its use was strictly voluntary and was not required to meet the educational objectives of either curriculum. The website
URL was provided to students at the beginning of the study via a link on the anatomy resource webpage, but was not added as a link to the online curriculum. In addition to the VAL, both cohorts had recommended readings in standard anatomy textbooks. To ensure a more arms-length evaluation of the VAL, we opted to not actively promote its use. There were no challenges with the implementation of the learning innovation.

\section{Evaluation}

Following three weeks of use, all students from both cohorts were invited to complete an

Table 1. Open-ended questions used to stimulate focus group discussion.

Semi-structured focus group questions

1. First, what do you like about the Virtual Anatomy Lab?

2. What did you not like about the Virtual Anatomy Lab? What could we do to improve?

3. Did the Virtual Anatomy Lab impact your learning?

4. Is the Virtual Anatomy Lab a valuable tool for teaching anatomy?

5. How would you like to see the Virtual Anatomy Lab used in the curriculum?

6. Any other comments?

Table 2. Compiled results of two focus group discussions on the Virtual Anatomy Laboratory grouped by emerging themes and by comment characteristic.

\begin{tabular}{|c|c|c|c|}
\hline & Element & Success & Challenge \\
\hline \multirow[t]{7}{*}{$\begin{array}{l}\text { Likes and } \\
\text { dislikes }\end{array}$} & Virtual lecture & - Virtual lectures were useful if you were new to the material & $\begin{array}{l}\text { - Virtual lectures were slow } \\
\text { - Virtual lectures were less engaging }\end{array}$ \\
\hline & $\begin{array}{l}\text { Video } \\
\text { demonstrations }\end{array}$ & $\begin{array}{l}\text { - Enjoyed video demonstrations } \\
\text { - Demonstrations were motivating and engaging. Students } \\
\text { enjoyed the break from reading textbooks and online } \\
\text { notes and appreciated the more visual way of learning. } \\
\text { - Demonstrations helped with revision of the material after } \\
\text { the laboratory session }\end{array}$ & $\begin{array}{l}\text { - Video demonstrations were sometimes too fast } \\
\text { - Students would like increased subdivision } \\
\text { of topics within the video demonstrations }\end{array}$ \\
\hline & Notes & - Notes were excellent & - Consider adding relevant images to the notes \\
\hline & Enhanced Visual Learning & & - Navigation for EVL was cumbersome \\
\hline & & - loved quizzes & $\begin{array}{l}\text { - Would like more questions and longer quizzes } \\
\text { - Navigation was noted as cumbersome by one group }\end{array}$ \\
\hline & Pedagogical Agent & - eDemonstrator was funny, motivating and engaging & \\
\hline & & $\begin{array}{l}\text { - Students liked the way she linked everything together } \\
\text { - Not considered distracting }\end{array}$ & \\
\hline \multicolumn{2}{|c|}{ Learning impact } & $\begin{array}{l}\text { - Excellent teaching tool } \\
\text { - Motivating and engaging, fun way to study } \\
\text { - Portability and accessibility of the VAL made learning } \\
\text { anatomy possible outside the lab }\end{array}$ & \\
\hline \multicolumn{2}{|l|}{ Value } & $\begin{array}{l}\text { - Good study guide } \\
\text { - Loved clinical aspect } \\
\text { - Different way to learn } \\
\text { - Have info without going to the lab }\end{array}$ & $\begin{array}{l}\text { - Objectives were long and repetitive, but students } \\
\text { still wanted them listed }\end{array}$ \\
\hline \multicolumn{2}{|c|}{$\begin{array}{l}\text { Purpose } \\
\text { (as seen by the students) }\end{array}$} & $\begin{array}{l}\text { - Should be used as an introduction to anatomy labs, } \\
\text { especially in a self-learning style curriculum } \\
\text { - Could be used also for pre-lab preparation and revision }\end{array}$ & \\
\hline
\end{tabular}


anonymous survey and to participate in one of two focus groups (approved by the Ottawa Hospital Research Ethics Board).

While the survey response rate was too low to draw meaningful conclusions, our focus groups permitted evaluation of the VAL. We held two focus groups with 8 participants each from both cohorts, conducted by a facilitator not directly involved in the project. The facilitator asked five open-ended questions to stimulate discussion (Table 1). Results were analyzed for emergence of themes and were further classified as likes/dislikes, learning impact, value or purpose statements (Table 2) or as suggestions for improvement (Table 3). of the learning resources, the video demonstrations were considered the most valuable, as students felt they were a novel, visual way to study and they appreciated learning outside the lab. While students also enjoyed the quizzes and study notes, they uniformly felt that the virtual lectures were less engaging and slow, and would only be of interest to someone with little or no background in anatomy.

Although not specifically asked to comment on the pedagogical agent, participants liked the inclusion of this aspect, and found her funny, motivating and engaging (Table 2). This result supports previous research indicating that use of a pedagogical agent can stimulate student engagement and suggests that use of a pedagogical agent could improve online learning environments in medicine. ${ }^{9}$

When asked if the VAL was a valuable tool, participants noted that the multiple modes of content delivery and the flexibility of off-site use as asserts, and unanimously felt that the VAL would be a useful introduction to the anatomy labs and a powerful review tool. Participants also made numerous suggestions for improvement, many of which have been implemented (Table 3). Notably, participants stressed that the content must i) closely follow the curriculum, with neither more, nor less content than required for the exam and; ii) that the tool should be formally linked to the curriculum and recommended by professors if it is to be used extensively. Indeed, students stressed that economy of time was of utmost importance to them and they were not compelled to try any innovations that were not assured to be of great use for the material being studied. Thus it is essential to tailor online learning resources to the curriculum of a particular medical school rather than rely on tools, commercial or otherwise, designed with a broader focus.

Usage statistics captured using Google Analytics reveal an increase in page views and visits in the September/October (when the lower limb is taught) and a concomitant decrease in new visitors, reflecting the adoption of the VAL by our students (Figure 1).

Further avenues of research should include peer review of the VAL and direct evaluation of the VAL's ability to supplement student achievement. We could capture student performance on formative quizzes within the VAL using both pre- and post-tests to assess student learning and assess the time on task required for anatomy exam preparation for VAL users versus non-users.

\section{Conclusions}

Our experience indicates that the judicious use of a pedagogical agent such as the eDemonstrator, is viewed as both motivating and engaging for students and thus is a viable low cost, low effort solution to the threat of decreased student engagement with the introduction of more self-directed learning into our medical curricula. We conclude that while interaction with faculty and with cadaveric

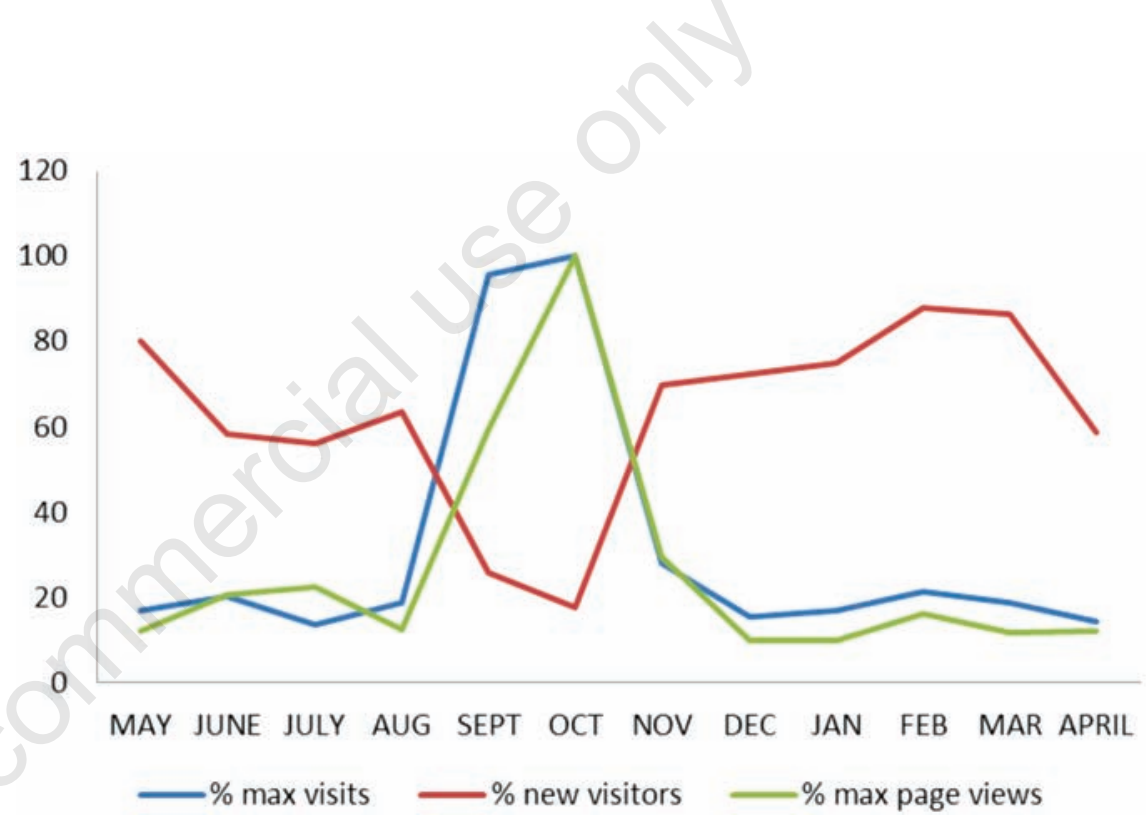

Figure 1. Usage of the Virtual Anatomy Lab as captured by Google Analytics from May 2010 to April 2011. The site visits and page views are shown as a percentage of the maximum, achieved in October 2011 (118 visits and 768 page views). The percentage of unique visitors as calculated by Google Analytics is also shown.

Table 3. Suggestions for iprovement for the Virtual Anatomy Lab.

\begin{tabular}{|c|c|c|}
\hline Theme & Improvement-oriented suggestions & Implemented suggestions \\
\hline Accessibility & $\begin{array}{l}\text { - Improve navigation } \\
\text { - Link to the curriculum formally } \\
\text { - Allow skip of the objectives }\end{array}$ & $\begin{array}{l}\text { - Ability to skip through the learning objectives } \\
\text { - Easier navigation within the VAL with enhanced menu buttons }\end{array}$ \\
\hline Learning resources & $\begin{array}{l}\text { - Add tips to the virtual demonstrations } \\
\text { - Further subdivide topics } \\
\text { - Longer quizzes } \\
\text { - Overview lecture/review lecture } \\
\text { - Add movements to the video demonstrations } \\
\text { - Incorporate radiology }\end{array}$ & - Further subdivision of video demonstrations \\
\hline Value & $\begin{array}{l}\text { - Should be endorsed by professors } \\
\text { - Believe the tool should closely follow the curriculum } \\
\text { - Should be used to prepare for lab }\end{array}$ & $\begin{array}{l}\text { - VAL is linked to the online medical curriculum } \\
\text { - Objectives remain aligned with the curricular objectives }\end{array}$ \\
\hline
\end{tabular}


specimens remains a cornerstone in the professional development of medical students, there is real benefit to using human pedagogical agents in online learning resources for topics that are essential but no longer fit into the modern curriculum.

\section{References}

1. Muller S. Physicians for the twenty-first century: report of the project panel on the general professional education of the physician and college preparation for medicine. J Med Educ 1984;59:1-208.

2. Michaelsen LK, Watson WE, Cragin JP, Fink LD. Team-based learning: a potential solution to the problems of large classes. Exchange: The Organizational Behavior Teaching Journal 1982;7:18-33.

3. Nieder GL, Parmelee DX, Stolfi A, Hudes PD. Team-based learning in a medical gross anatomy and embryology course. Clin Anat 2005;18:56-63.

4. Vasan N, DeFouw D, Holland B. Modified use of team-based learning for effective delivery of medical gross anatomy and embryology. Anat Sci Educ 2008;1:3-9.

5. Vasan NS, DeFouw D0, Compton S. Teambased learning in anatomy: an efficient, effective, and economical strategy. Anat Sci Educ 2011:333-9.

6. Willms JD, Friesen S, Milton P. What did you do in school today? Transforming classrooms through social, academic and intellectual engagement. (First National Report). Toronto, ON: Canadian Education Association; 2009.

7. Bangert AW. The seven principles of good practice: a framework for evaluating online teaching. The Internet and Higher Education 2004;7:217-32.

8. Chickering A, Gamson Z. Seven principles for good practice in undergraduate education. AAHE bulletin. Available from: http://www.uis.edu/liberalstudies/stu- dents/documents/sevenprinciples.pdf

9. Lester JC, Converse SA, Kahler SE, et al. The persona effect: affective impact of animated pedagogical agents. CHI '97 Proceedings of the SIGCHI conference on Human factors in computing systems. Available from: http://citeseerx.ist.psu.edu/ viewdoc/download?doi=10.1.1.91.8779\&re $\mathrm{p}=$ rep1\&type $=$ pdf

10. Walker J, Sproull L, Subramani R. Using a human face in an interface. Proceedings of CHI'94, 1994. Available from: http:// smg.media.mit.edu/library/UsingHumanF aceInterface.pdf Accessed on: July 15, 2012.

11. Pottier P, Hardouin JB, Hodges BD, et al. Exploring how students think: a new method combining think-aloud and concept mapping protocols. Med Educ 2010; 44:926-35.

12. Baylor A, Kim Y. Simulating instructional roles through pedagogical agents. International Journal fo Artificial Intelligence in Education 2005;15. 